\title{
Cricotireoidotomia modificada: opção para remoção das secreções traqueobrônquicas*
}

\author{
Wilson Paloschi Spiandorello ${ }^{1}$, Darcy Ribeiro Pinto FilHO ${ }^{2}$, \\ Gisele BASSANi ${ }^{3}$, FRANCA STEDILE ANGELI SPIANDORELlO 4
}

Introdução: As medidas naturais para remoção das secreções traqueobrônquicas, como nebulizações, drenagem postural e fisioterapia respiratória, nem sempre são efetivas. Objetivo: Avaliar uma técnica cirúrgica alternativa, a cricotireoidotomia modificada, para aspiração das secreções traqueobrônquicas.

Método: A cricotireoidotomia modificada consiste na introdução de uma sonda uretral $\mathrm{n}^{\circ} 8,10$ ou

12 , na membrana cricotireoidiana para estimular a tosse e aspirar secreções. Foi feito um estudo descritivo dos benefícios e complicações imediatas e tardias do uso dessa técnica em 45 pacientes com secreções traqueobrônquicas excessivas inadequadamente removidas pelos métodos habituais.

Resultados: As complicações cirúrgicas imediatas foram sangramento local (10 pacientes), desvio de orofaringe (três), enfisema subcutâneo (um) e dificuldade de introdução (um). O tempo médio de permanência do cateter foi de $14 \pm 16$ dias. Em todos os casos o cateter provocou tosse e permitiu a aspiração das secreções com facilidade. A intercorrência mais freqüente (17 pacientes) foi a expulsão do cateter por tosse, seu manuseio inadequado nas aspirações e movimentação dos pacientes.

Conclusão: Esta é uma técnica simples, com baixa morbidade, sendo uma alternativa efetiva para a aspiração de secreções traqueobrônquicas. (J Pneumol 2002;28(2):61-64)

\section{Modified crichothyroidotomy: an alternative for tracheobronchial secretions removal}

Introduction: Inhalations, postural drainage and respiratory physiotherapy are not always effective in removing tracheobronchial secretions. Objectives: To evaluate an alternative surgical technique, modified crichothyroidotomy, to aspirate tracheobronchial secretions. Method:

Modified crichothyroidotomy is the introduction of a catheter number 8,10 or 12 into the crichothyroid membrane in order to stimulate coughing and the aspiration of secretions. This is a descriptive study of the benefits as well as immediate and late complications caused by the use of this technique in 45 patients with excessive tracheobronchial secretions inadequately removed by

usual methods. Results: Immediate surgical complications were bleeding (10 patients), oropharynx deviation (3), subcutaneous emphysema (1) and difficult introduction (1). Mean catheter permanence was $14 \pm 16$ days and, in all cases, the catheter provoked coughing and allowed the easy aspiration of secretions. The most frequent occurrence (17 patients) was the expulsion of the catheter by coughing, inadequate catheter handling during aspiration and moving of the patients. Conclusion: This is a simple technique with a low morbidity rate and represents constitutes an effective alternative to be used in the aspiration of tracheobronchial secretions.

Descritores - Drenagem postural. Aspiração.

* Trabalho realizado na Clínica do Pulmão - Caxias do Sul, RS.

1. Professor Titular da Disciplina de Pneumologia e Cirurgia Torácica do Curso de Medicina da Universidade de Caxias do Sul, RS; Doutor em Medicina - Pneumologia - pela Universidade Federal do Rio Grande do Sul (UFRGS).

2. Professor da Disciplina de Pneumologia e Cirurgia Torácica; Mestre em Medicina; Responsável pelo Serviço de Cirurgia Torácica.
Key words - Postural drainage. Aspiration.

3. Doutoranda em Medicina; Pneumologista.

4. Acadêmica de Medicina.

Endereço para correspondência - Wilson Paloschi Spiandorello, Rua Santos Dumont, 839, apto. 15 - 95084-390 - Caxias do Sul, RS. Email:Wilsonsp@terra.com.br

Recebido para publicação em 15/2/01. Aprovado, após revisão, em 10/12/01. 


\section{INTRODUÇÃO}

A retenção de secreções na árvore traqueobrônquica pode causar atelectasias e outras obstruções incompletas de vias aéreas, ocasionando desproporção na relação ventilação perfusão, predispondo a infecções e insuficiência respiratória (hipoxemia e/ou hipercapnia). Dentre as infecções respiratórias, a pneumonia assume papel importante, por estar associada à sepse e ao óbito. A permeabilidade das vias aéreas obtidas pela limpeza das suas secreções pode ser auxiliada pelas ações das equipes médicas e de enfermagem.

A associação de nebulizações com solução fisiológica à fisioterapia respiratória pode ser eficaz, em grande número de casos, para mobilizar e remover secreções traqueobrônquicas. Porém, essa associação pode não ser efetiva nos estágios mais avançados de DPOC, no pósoperatório imediato de cirurgia torácica ou de abdômen superior, em pacientes com seqüelas neurológicas restritos ao leito e com diminuição do reflexo da tosse. Para esses pacientes, poderá ser necessária aspiração das secreções diretamente nas vias aéreas. No arsenal de métodos que possibilitam a aspiração direta das secreções da árvore brônquica disponíveis temos: aspiração nasotraqueal; intracath traqueal; fibrobroncoscopia e traqueostomia.

Na tentativa de testar métodos alternativos para limpeza da árvore traqueobrônquica, McCabe et al. ${ }^{(1)}$, em 1962, facilitaram a via de acesso à traquéia, através da punção da membrana cricotireóidea, e concluíram ser útil no pósoperatório de pacientes idosos, debilitados, obesos e não cooperativos. Em 1984 Matthews e Hopkinson ${ }^{(2)}$ descrevem a minitraqueostomia, que consiste na introdução de cânulas pela membrana cricotireóidea, fixadas na pele, através da qual são introduzidos cateteres para as aspirações de secreções. Em 1998, Vianello e Bevilacqua ${ }^{(3)}$ reforçaram a utilidade da mesma no manejo de pacientes neurológicos. Brantigan e $\mathrm{Crow}^{(4)}$ descreveram a cricotireoidotomia que, por sua vez, foi modificada pelos autores, empregando sondas uretrais (utilizadas para sondagem vesical de alívio) $n^{\circ} 8,10$ ou 12 , introduzidas na traquéia diretamente através da membrana cricotireoidiana e, fixadas na pele, facilitando as aspirações de secreções traqueobrônquicas. A sonda foi denominada de cateter traqueal. Esse trabalho teve como objetivos avaliar a efetividade em aspirar secreções traqueobrônquicas e as complicações da cricotireoidotomia.

\section{Material e MÉTOdos}

No intuito de avaliar a técnica proposta, realizou-se um estudo descritivo de uma coorte de 45 pacientes, que observou a capacidade do cateter traqueal em remover as secreções traqueobrônquicas, através de aspirações e es- tímulo de tosse, e as complicações imediatas e tardias associadas à cricotireoidotomia modificada.

Foram incluídos pacientes com secreções traqueobrônquicas excessivas, inadequadamente removidas após nebulizações, drenagem postural e fisioterapia respiratória, ou quando estes métodos eram contra-indicados. Foram excluídos os pacientes que usavam anticoagulantes em doses terapêuticas, a atividade da protrombina era menor que $60 \%$, a contagem das plaquetas inferior a $60.000 \mathrm{~mm}^{3}$ e portadores de asma brônquica.

A freqüência com que se aspiravam as secreções esteve relacionada à necessidade clínica. Habitualmente, a cada duas horas eram instilados 3 a $5 \mathrm{ml}$ de soro fisiológico com mobilização manual do cateter através de movimentos suaves de intrusão e extrusão, não ultrapassando $2 \mathrm{~cm}$ pelo risco de retirada acidental da sonda. O tempo máximo de cada aspiração não deveria ultrapassar os 10 segundos.

Mantinha-se o orifício de entrada do cateter sempre limpo, lavando-o com água destilada ou soro fisiológico. Não se ocluía o orifício de entrada do cateter com gaze, para não esconder secreções que ali poderiam acumularse.

As variáveis analisadas neste estudo foram: a técnica do procedimento, a manutenção do cateter, a sua efetividade em aspirar as secreções e estimular a tosse. Descreveram-se os sexos, as idades e as indicações, estratificadas em doenças neurológicas, pulmonares ou pós-operatórios. Registraram-se, também, as complicações e o tempo de permanência do cateter.

O método foi considerado efetivo quando as secreções eram removidas adequadamente, sem necessidade de introdução de outros métodos.

\section{DESCRIÇÃO DA TÉCNICA}

Material cirúrgico básico: Foram utilizadas sondas uretrais $\mathrm{n}^{\circ} 8,10$ ou 12; pinças de dissecção ("mosquito"); bisturi lâmina $\mathrm{n}^{\circ} 11$ ou 15 ; e lidocaína a $2 \%$ com vasoconstritor.

Descrição do procedimento cirúrgico:

1) O paciente é posicionado em hiperextensão cervical, com coxim sob os ombros;

2) Palpação digital para identificação da membrana cricotireoidiana;

3) Botão anestésico com lidocaína a $2 \%$ com vasoconstritor $(5 \mathrm{ml})$;

4) Incisão longitudinal ou transversal na linha média da membrana com extensão de aproximadamente $5 \mathrm{~mm}$. A dissecção dos planos subcutâneo e muscular é feita com o cuidado técnico de permanecer na linha média cervical, evitando, dessa forma, sangramento mais expressivo durante o procedimento; 
5) Exposição da membrana cricotireoidiana;

6) Incisão da membrana com lâmina de bisturi ou pinça de dissecção ("mosquito"). A pinça é mantida na luz traqueal e serve de guia para a introdução da sonda no sentido caudal;

7) Sangramentos da incisão são controlados por compressão digital;

8) A sonda é introduzida aproximadamente $10 \mathrm{~cm}$ no interior da traquéia e fixada à pele com fitas adesivas.

\section{RESULTADOS}

Foram estudados 45 pacientes, sendo 36 (80\%) do sexo masculino e nove (20\%) do feminino. A idade mínima foi de 12 anos e a máxima, de 87 anos, com média de 61,4 e desvio padrão de 17,1 anos. O tempo de permanência do cateter variou de um dia até 545 dias. O segundo tempo mais prolongado de uso foi de 90 dias. O tempo máximo, por ser caso único, foi excluído dos cálculos da média de permanência. Excluído esse caso, a média foi de 14 dias, com desvio padrão de 16 dias.

Os pacientes foram agrupados conforme sua doença de base, sendo que $17(37,4 \%)$ foram enquadrados no grupo de doenças neurológicas, $15(33,0 \%)$ no de doenças respiratórias e $13(28,6 \%)$ como pós-operatório de cirurgia torácica. Dos pacientes com doenças respiratórias, à exceção de um caso de seqüela de tuberculose, os demais preenchiam os critérios diagnósticos de DPOC.

O procedimento foi realizado em 35 casos (77\%) na UTI, em nove casos $(19,8 \%)$ no bloco cirúrgico e em um caso $(2,2 \%)$ no quarto de um setor do hospital.

A Tabela 1 descreve as complicações cirúrgicas. Ao longo do seguimento, não foram observados sintomas clínicos de estenose traqueal nos 30 pacientes sobreviventes que integraram este estudo.

A intercorrência mais freqüente foi a expulsão do cateter em 17 casos (37,4\%). A tosse, o manuseio inadequado nas aspirações e os movimentos voluntários e involuntários dos pacientes foram identificados como fatores causais da expulsão acidental. Contudo, nas primeiras 24 horas da retirada acidental dos cateteres, foi possível reintroduzi-los com certa facilidade pelo orifício prévio, evitando novo procedimento.
Em todos os pacientes o cateter provocou tosse e foi capaz de aspirar as secreções com facilidade. Dos 45 casos, houve necessidade de conversão em traqueostomia em dois pacientes $(4,4 \%)$ e em $10(22 \%)$ a intubação translaríngea foi indicada. Sete $(10 \%)$ desses 10 pacientes foram intubados por insuficiência respiratória; em dois $(20 \%)$, não havia indicação para cricotireoidotomia; e em um caso $(10 \%)$ a indicação de intubação pelo médico assistente não preenchia nenhuma das indicações formais para realização de tal procedimento.

Da amostra estudada, 15 (33\%) pacientes evoluíram para óbito por sua doença básica. Dois pacientes continuaram com o cateter após a alta hospitalar. Num desses pacientes o cateter foi manuseado por familiares $e$, no outro, por auxiliar de enfermagem.

\section{Discussão}

A aspiração nasotraqueal, descrita no início deste século $^{(5)}$, consiste na introdução de sonda através da narina para atingir a laringe e provocar tosse, ou ultrapassá-la e aspirar secreções traqueobrônquicas. Essa técnica, contudo, tem indicação restrita, por ser método que ocasiona desconforto demasiado aos pacientes com algum grau de lucidez, além de necessitar de profissional treinado para a sua realização.

A intubação translaríngea, oro ou nasotraqueal, permite a aspiração de secreções em pacientes que necessitem de ventilação mecânica. No entanto, o seu uso prolongado, acima de 10 dias, poderá acarretar morbidades, tais como ulcerações e estenoses traqueais ${ }^{(6,7)}$.

Pode-se usar a traqueostomia com o único intuito de remoção das secreções traqueobrônquicas. Porém, mais freqüentemente, ela é empregada nos pacientes em ventilação mecânica prolongada em substituição à intubação translaríngea(8-10). O espaço cricotireoidiano é uma via de acesso à traquéia, da mesma forma que através da orofaringe (intubação) e do pescoço (traqueostomia). Neste estudo, as vantagens desse método sobre a intubação orotraqueal ou nasotraqueal para a aspiração de secreções foram: maior conforto para o paciente; possibilidade de maior tempo de permanência e menores complicações. As vantagens em relação à traqueostomia foram: menor

TABELA 1

Complicações associadas à cricotireoidotomia modificada

\begin{tabular}{lrlll}
\hline \multicolumn{1}{c}{ Imediatas } & $\mathrm{N}(\%)$ & \multicolumn{1}{c}{ Tardias } & $\mathrm{N}(\%)$ \\
\hline Sangramento local & $10(22 \%)$ & Sangramento pelas aspirações & $3(6,6 \%)$ \\
Desvio orofaringe & 3 & $(6,6 \%)$ & Deslocamento pela tosse & $2(4,4 \%)$ \\
Enfisema subcutâneo & 1 & $(2,2 \%)$ & Broncoespasmo & $1(2,2 \%)$ \\
Dificuldade de introdução & 1 & $(2,2 \%)$ & Granuloma na traquéia & $1(2,2 \%)$ \\
\hline
\end{tabular}


custo, maior facilidade de realização, maior facilidade de manutenção e menores complicações. A grande desvantagem em comparação com os outros dois métodos foi que a cricotireoidotomia modificada não serve para a administração concomitante de oxigênio. A presença de balonete na intubação traqueal e traqueostomia pode ter algumas vantagens, especialmente na vedação aérea. Porém, também possui desvantagens, principalmente nas estenoses, ulcerações ou fístulas que podem produzir. Em qualquer um dos três métodos o mecanismo de aspiração das secreções traqueobrônquicas é o mesmo; introduz-se a mesma sonda e aspira-se da mesma maneira.

A fibrobroncoscopia é eficaz para a remoção das secreções endobrônquicas por possuir aspirador de calibre considerável e permitir a visão direta da árvore brônquica. Representa o método de escolha em pacientes de UTI com atelectasia pulmonar parcial ou total ${ }^{(11)}$. Porém, o custo elevado do exame e a necessidade de profissional capacitado em endoscopia respiratória podem restringir seu uso, enquanto a cricotireoidotomia modificada, além de não ter esses inconvenientes, permite aspirações de secreções traqueobrônquicas repetidamente.

Na década de 60 surgiu um método inovador para estímulo de tosse e aspiração de secreções das vias aéreas. Radigan et al. ${ }^{(12)}$ descreveram o intracath traqueal (cateter utilizado para canulação de veias de grosso calibre) como um dispositivo intratraqueal introduzido através da membrana cricotireóidea. Apesar da facilidade técnica de introdução e do baixo índice de complicações, esse método, capaz de estimular eficazmente a tosse, possui como maior inconveniente o pequeno calibre, que dificulta a aspiração de secreções, especialmente as mais espessas. $\mathrm{O}$ intracath traqueal e a cricotireoidotomia modificada são os métodos que melhor preservam a fisiologia respiratória normal. Tanto a intubação orotraqueal quanto a traqueostomia interferem no mecanismo da tosse por não permitir o fechamento da glote, enquanto o método testado não intervem. Para a expulsão eficaz das secreções traqueobrônquicas através da tosse, todo o seu mecanismo deve estar funcionante. A permanência da glote aberta impede de formarem-se pressões intratorácicas positivas, com conseqüentes perdas das forças de explosão de ar e das secreções.

O grosso calibre das sondas empregadas para a aspiração das secreções pelo método da cricotireoidotomia modificada resolveu a maior deficiência do intracath traqueal, o pequeno calibre, mantendo a capacidade de estímulo de tosse e facilitando a remoção.

A aspiração de secreções traqueobrônquicas precisa ser feita com técnica adequada; por isso, são necessárias pessoas capacitadas. O treinamento dessas pessoas é fundamental para o sucesso. Na série estudada, as aspirações foram realizadas eficientemente por médicos, enfermei- ros, auxiliares de enfermagem e até mesmo por familiares do paciente. Os últimos, demonstrando a facilidade de realização por pessoas que se dispõem a aprender a técnica e a executá-la, sem ser profissional ligado à área da saúde.

Por fim, a facilidade de reposição das sondas nas primeiras 24 horas da sua retirada acidental pelo mesmo orifício já existente e a facilidade de realizar aspirações repetidas, necessitando somente a conexão da sonda com um aspirador, tornam o cateter traqueal, introduzido pela membrana cricotireoidiana, uma opção para a remoção das secreções pulmonares.

Os resultados observados nesta série de pacientes submetidos à cricotireoidotomia modificada permitiu a conclusão de que é uma técnica simples, associada a baixa morbidade, sendo uma alternativa efetiva para a aspiração das secreções traqueobrônquicas e para o estímulo da tosse nos pacientes impossibilitados de removê-las espontaneamente.

Fazem-se necessárias comparações com outros métodos utilizados para remoção de secreções da árvore traqueobrônquica através de estudos prospectivos e randomizados para definir as suas indicações.

\section{REFERÊNCIAS}

1. McCabe R, Reid WM, Knox WG. Evaluation of the use of a temporary percutaneous endotracheal catheter in the treatment and prevention of postoperative pulmonary complications. Ann Surg 1962;156: 5-8.

2. Matthews HR, Hopkinson RB. Treatment of sputum retention by minitracheotomy. Br J Surg 1984;71:147-50

3. Vianello A, Bevilacqua M. Prevention of pulmonary morbidity in patients with neuromuscular disorders: a possible role for permanent cricothyroid minitracheostomy, Chest 1998;114:346-7.

4. Brantigan CO, Crow JB. Cricothyroidotomy: elective use in respiratory problems requiring tracheotomy. J Thorac Cardiovasc Surg 1976; 71:72-80

5. Haight $\mathrm{C}$. Intratracheal suction in the management of postoperative pulmonary complications. Ann Surg 1938;107:218-28.

6. Kastanos N, Miro RE, Perez AM. Laryngotracheal injury due to endotracheal intubation: incidence, evolution, and predisposing factors: a prospective long-term study. Crit Care Med 1983;11:362-6.

7. Stauffer JL, Olson DE, Petty TL. Complications and consequences of endotracheal intubations and tracheotomy: a prospective study of 150 critically ill adult patients. Am J Med 1981;70:65-76.

8. Astrachan D, Kirchner JC, Goodwin WJ. Prolonged intubation vs. tracheotomy: complications, practical and psychological considerations. Laringoscope 1988;98:1165-9.

9. Wood DE. Tracheotomy. Chest Surg Clin N Am 1996;6:749-64.

10. Heffner JE, Miler SK, Sahn AS. Tracheotomy in the intensive care unit 2: complications. Chest 1986;90:430-6.

11. Pinto DR. Papel da cirurgia torácica na unidade de terapia intensiva. In: Silva LC, editor. Condutas em pneumologia. $1^{\text {a }}$ ed. Rio de Janeiro: Revinter, 2000;842-9.

12. Radigan LR, King RD. A technique for the prevention of postoperative atelectasis. Surgery 1960;47:184-7. 